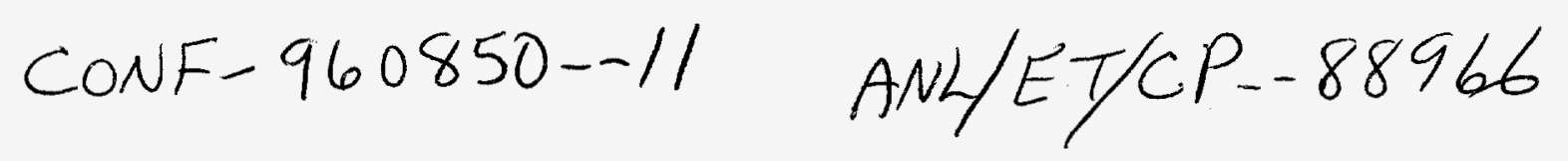

\title{
Prediction of Burnout of a Conduction-Cooled BSCCO Current Lead*
}

\author{
S. Y. Seol
}

Department of Mechanical Engineering, Chonnam National University, Kwangju 700-757, Korea

Y. S. Cha, R. C. Niemann, and J. R. Hull

Energy Technology Division, Argonne National Laboratory, Argonne, IL 60439, USA

SEP 03 १९SO

OSTI

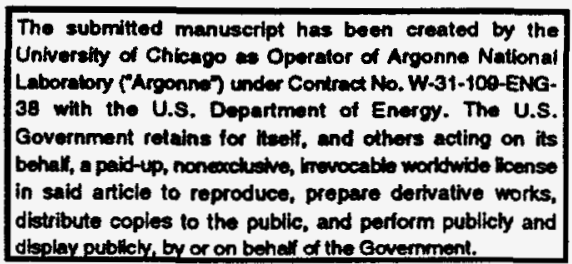

Distribution

1. R. W. Weeks

2. R. B. Poeppel

3. U. Balachandran

4. R. A. Valentin

5. Authors

6. ESA Section

7. B. Baudino

8. F. Y. Fradin

9. H. Drucker

10. S. Lake

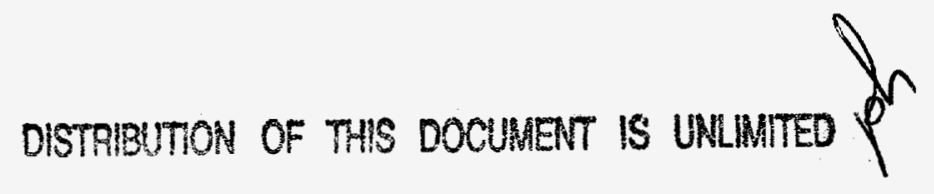

For presentation at 1996 Applied Superconductivity Conference, August 25-30, 1996, Pittsburgh, PA, and publication in IEEE Transactions on Applied Superconductivity.

*Work supported by the U.S. Department of Energy, Energy Efficiency and Renewable Energy, as part of a program to develop electric power technology, under Contract W-31-109-Eng-38. 


\section{DISCLAIMER}

Portions of this document may be illegible in electronic image products. Images are produced from the best available original document. 


\section{DISCLAIMER}

This report was prepared as an account of work sponsored by an agency of the United States Government. Neither the United States Government nor any agency thereof, nor any of their employees, makes any warranty, express or implied, or assumes any legal liability or responsibility for the accuracy, completeness, or usefulness of any information, apparatus, product, or process disclosed, or represents that its use would not infringe privately owned rights. Reference herein to any specific commercial product, process, or service by trade name, trademark, manufacturer, or otherwise does not necessarily constitute or imply its endorsement, recommendation, or favoring by the United States Government or any agency thereof. The views and opinions of authors expressed herein do not necessarily state or reflect those of the United States Government or any agency thereof. 


\title{
Prediction of Burnout of a Conduction-Cooled BSCCO Current Lead
}

\author{
S. Y. Seol \\ Department of Mechanical Engineering, Chonnam National University, Kwangju 700-757, Korea \\ Y. S. Cha, R. C. Niemann, and J. R. Hull \\ Energy Technology Division, Argonne National Laboratory, Argonne, IL 60439, USA
}

\begin{abstract}
A one-dimensional heat conduction model is employed to predict burnout of a $\mathrm{Bi}_{2} \mathrm{Sr}_{2} \mathrm{CaCu}_{2} \mathrm{O}_{8}$ current lead. The upper end of the lead is assumed to be at $77 \mathrm{~K}$ and the lower end is at $4 \mathrm{~K}$. The results show that burnout always occurs at the warmer end of the lead. The lead reaches its burnout temperature in two distinct stages. Initially, the temperature rises slowly when part of the lead is in flux-flow state. As the local temperature reaches the critical temperature, it begins to increase sharply. Burnout time depends strongly on flux-flow resistivity.
\end{abstract}

\section{INTRODUCTION}

High-temperature superconductor (HTS) current leads are advantageous because they have the potential to reduce refrigeration requirements to significantly below the best values achievable with conventional leads [1]. Various HTS materials were considered as candidates for certain applications [1]-[7]. Because of the relatively high current in the leads, any small resistance in the lead may lead to burnout by Joule heating.

Burnout of current leads has been studied for conventional [8], [9] and superconducting [5]-[7] current leads. In [7], it was assumed that the entire HTS lead suddenly becomes normal, and the results represent the most conservative estimate of burnout time. However, HTSs are known to have a much wider transition region between superconducting and normal states than conventional low-temperature superconductors. In this transition (flux-flow) state, resistivity is much lower than that in the normal state. Burnout predictions in this study were carried out by including the flux-flow (transition) state. A one-dimensional heat conduction model is employed and the temperatures at upper and lower ends of the lead are assumed to be fixed. The HTS lead is $\mathrm{Bi}_{2} \mathrm{Sr}_{2} \mathrm{CaCu}_{2} \mathrm{O}_{8}$ (BSCCO-2212) and is made by a melt-casting process.

Manuscript received August 28. 1996.

Work supported by the U.S. Department of Energy. Energy Efficiency and Renewable Energy, as part of a program to develop electric power technology, under Contract W-31-109-Eng-38.

\section{ANALYSIS}

The model employed for the conduction-cooled current lead is shown in Fig. 1. The BSCCO-2212 rod is a solid cylinder with diameter $d$ and length $L$. The cold end (lower end) is kept at $T_{L}(=4 \mathrm{~K})$, and the warm end (upper end) is at $T_{U}$. The warm-end temperature can be controlled by an intermediate heat intercept and the cold end is usually maintained at a temperature close to the saturation temperature of the cryogenic coolant. It is assumed that heat is transferred by conduction only in the axial direction of the BSCCO rod. This is a conservative assumption because no credit is taken for any heat transfer in the radial direction.

The calculation of burnout time of BSCCO-2212 current lead is based on the Fourier heat conduction equation:

$$
\gamma C(T) \frac{\partial T}{\partial t}=\frac{\partial}{\partial x}\left[k(T) \frac{\partial T}{\partial x}\right]+\rho J^{2}
$$

where $\gamma$ is density, $C$ is specific heat, $k$ is thermal conductivity, $\rho$ is electrical resistivity, and $J$ is current density. The boundary conditions are

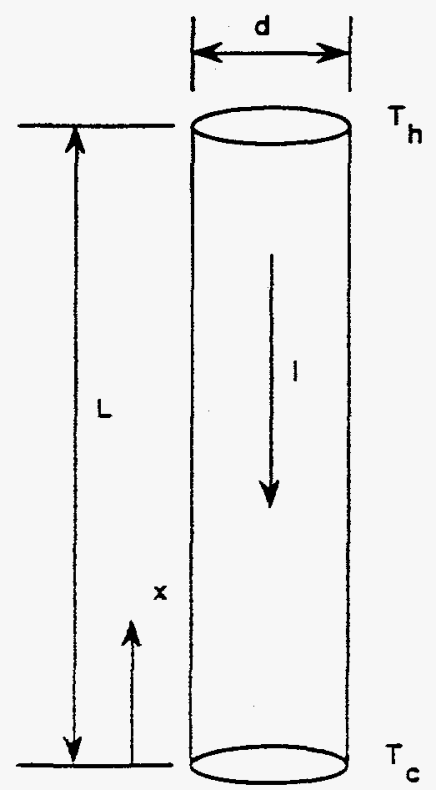

Fig. 1. Schematic diagram of current lead geonetry. 


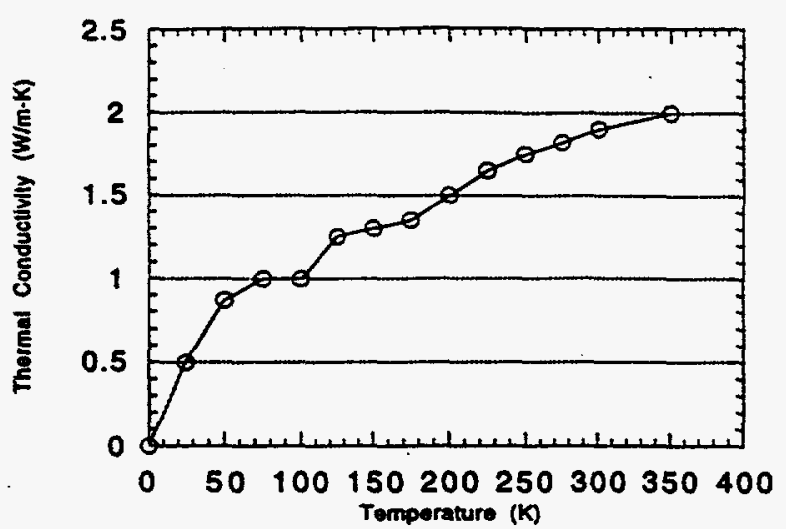

Fig. 2. Variation of thermal conductivity with temperature for BSCCO2212 lead.

$$
\begin{array}{ll}
T=T_{L} & \text { at } \mathrm{x}=0 \\
T=T_{U} & \text { at } \mathrm{x}=L .
\end{array}
$$

In this paper, we assume that the lower end of the lead is very close to a pool of liquid helium and $T_{L}=4 \mathrm{~K}$. The upper end of the superconductor lead is assumed to be intercepted by liquid nitrogen and $T_{U}=77 \mathrm{~K}$.

The thermal conductivity for the BSCCO-2212 lead is shown in Fig. 2, which comes from [4]. The thermal diffusivity of BSCCO-2212 can be obtained from [10]. The specific beat of BSCCO-2212 is calculated from the data of thermal conductivity and thermal diffusivity and is approximated by

$$
C=1.58 T \text {, }
$$

where $C$ is in $\mathrm{J} /(\mathrm{kg}-\mathrm{K})$ and $T$ is absolute temperature in Kelvins.

The objective of the burnout analysis is to estimate the time required for the maximum temperature of the lead to reach a specified value called burnout temperature. In this paper, burnout temperature is arbitrarily defined to be $T_{b}=$ $300 \mathrm{~K}$.

The finite-volume method is used to solve the partial differential equation (1) with boundary condition given by (2). A central difference scheme is employed for space coordinates. and a fully implicit scheme is employed for time.

\section{A. Superconducting State}

If the HTS lead is in the superconducting state, the resistance is zero and no Joule heat is generated. Temperature distribution along the lead can be obtained by solving (1) without the heat generation term.

$$
\frac{d}{d x}\left[k(T) \frac{d T}{d x}\right]=0
$$

The temperature distribution can be obtained by integrating (4):

$$
\frac{x}{L}=\frac{\int_{T_{L}}^{T(x)} k(T) d T}{\int_{T_{L}}^{T_{U}} k(T) d T} .
$$

By using the temperature dependent thermal conductivity data, we can calculate the temperature distribution in the superconducting steady state (Fig. 3). Two upper-end temperatures, $T_{U}=77$ and $60 \mathrm{~K}$, are considered. The upper curve of Fig. 3 is for $T_{U}=77 \mathrm{~K}$, and the lower curve is for $T_{U}=60 \mathrm{~K} . T_{L}=4 \mathrm{~K}$ in both cases. To calculate the burnout time, the temperature profile in the steady (superconducting) state is used as an initial condition for the lead.

The helium boiloff rate in the superconducting state can be calculated by [5]:

$$
\int_{T_{L}}^{T_{U}} k(T) d T=\left(\frac{\dot{m}}{I}\right)(J L) C_{L}=\frac{\dot{m} L C_{L}}{A}
$$

where $\dot{m}$ is the helium boiloff rate $(\mathrm{kg} / \mathrm{s})$, and $C_{L}$ is the latent heat of vaporization for liquid helium $\left(2.36 \times 10^{4}\right.$ $\mathrm{J} / \mathrm{kg}$ ). If the BSCCO-2212 rod is $15 \mathrm{~cm}$ long and has a diameter of $5 \mathrm{~mm}$, the calculated helium boiloff rate is $0.269 \mathrm{mg} / \mathrm{s}$ for $T_{U}=77 \mathrm{~K}$, and $0.178 \mathrm{mg} / \mathrm{s}$ for $T_{U}=60 \mathrm{~K}$.

\section{B. Critical Current Density}

The critical current density is primarily a function of temperature. The following equation for critical current density is a linear fit of a small number of values provided by the manufacturer of the BSCCO-2212 rod:

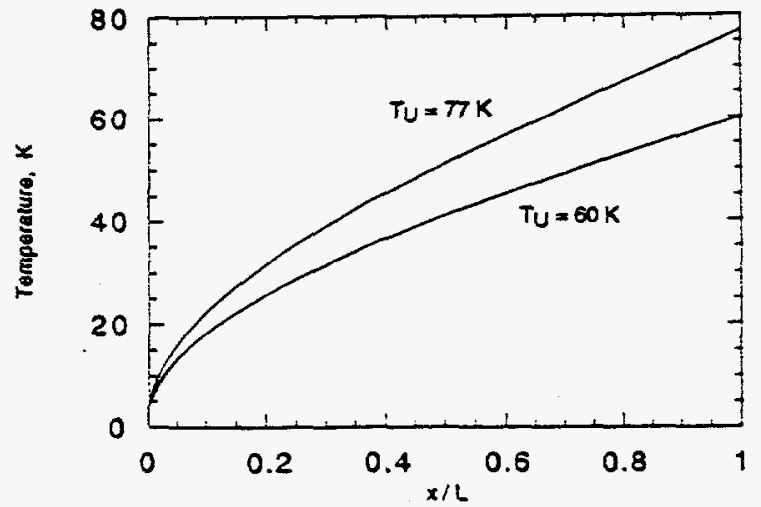

Fig. 3. Steady-state temperature profile of contuction-cooled BSCCO-2212 current lead. 


$$
J_{c}\left(A / \mathrm{cm}^{2}\right)=10728-116.64 T
$$

Although (7) gives critical temperature $T_{c}=91.9 \mathrm{~K}, T_{c}$ is assumed to be $90 \mathrm{~K}$ in this paper for conservative results.

Although the temperature of the superconductor is lower than the critical temperature, the conductor becomes resistive if the operating current density $J$ becomes higher than the critical current density $J_{c}(T)$. Consider an HTS current lead with a temperature distribution like that shown in Fig. 3. If the operating current is greater than the critical current at $T U$, part of the lead near the upper end becomes resistive. The temperature in the resistive region will increase and beat will be conducted toward the lower end of the lead where the temperature is lower. This increase in temperature will further lower the critical current density, and the resistive region will propagate toward the lower end of the lead. In this paper, the resistive regime is also referred to as the fluxflow regime, which is a transition regime between the superconducting and normal regimes. To calculate the temperature response, we must know the flux-flow resistivity of the BSCCO rod.

\section{Flux-Flow Resistivity}

In general, flux-flow resistivity $\rho_{f f}$ is a function of temperature, and only limited data [11] indicate that flux-flow resistivity increases with temperature. However, there are little or no data on flux-flow resistivity of a BSCCO-2212 superconductor. We have conducted experiments to measure the flux-flow resistivity of the BSCCO-2212 rod at $77 \mathrm{~K}$ (liquid nitrogen) and $87 \mathrm{~K}$ (liquid argon), and the results are shown in Fig. 4. The slope of the E-J curve gives the fluxflow resistivity $\left(\rho_{f f}=d E / d J\right)$. From the data shown in Fig. 4, the flux-flow resistivity of the BSCCO-2212 rod is estimated to be $\approx 10^{-6} \Omega-\mathrm{cm}$ and appears to be fairly insensitive to temperatures between 77 and $87 \mathrm{~K}$. Because there is a lack of data, the uncertainty in the flux-flow resistivity is relatively large. Therefore, in this paper, calculations are carried out by parametrically varying the flux-flow resistivity from $10^{-5}$ to $10^{-7} \Omega-\mathrm{cm}$.

In the numerical calculation, it is assumed that the lead is in the superconducting state if $T<T_{c}$ and $J<J_{c}(T)$, and the resistivity is zero. The lead is assumed to be in the resistive (flux-flow) state if $T<T_{c}$ and $\left.J\right\rangle J_{c}(T)$ and the resistivity is equal to $\rho_{f f}$. The lead is in normal state if $T<T_{c}$ and the resistivity is equal to the normal state resistivity $\rho_{n}$. Resistivity of the BSCCO rod under normal state is $2.5 \mathrm{x}$ $10^{-3} \Omega$-cm at $300 \mathrm{~K}$ and $0.8 \times 10^{-3} \Omega-\mathrm{cm}$ at $92 \mathrm{~K}$. Between 92 and $300 \mathrm{~K}$, normal state resistivity is calculated by linear interpolation.

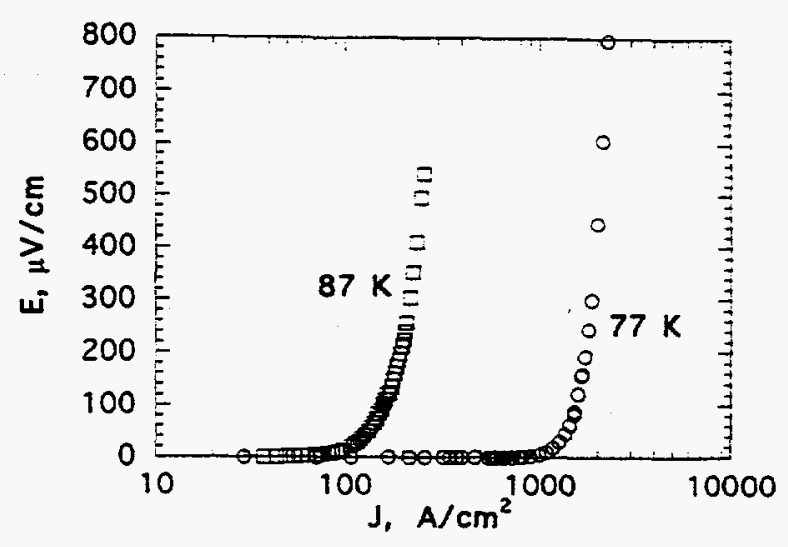

Fig. 4. $E-J$ characteristics of melt-cast BSCCO-2212 rod.

\section{RESULTS AND DISCUSSION}

Fig. 5 shows change of temperature with time by using a flux-flow resistivity of $10^{-6} \Omega-\mathrm{cm}$ and an operating current of $400 \mathrm{~A}$. Because heat generation is concentrated near the warmer end, temperature rise is also concentrated there. Initially, the rise in temperature is very slow due to the relatively low resistivity of flux flow state. When the temperature reaches the critical point, $(90 \mathrm{~K})$, it rises rapidly because there is a sudden increase in resistivity. Once the warmer end becomes normal, the lead reaches its burnout temperature $(300 \mathrm{~K})$ in a very short time, as shown in Fig. 5. While $2.8 \mathrm{~s}$ are needed for the temperature to rise from $77 \mathrm{~K}$ to $90 \mathrm{~K}$, only $0.1 \mathrm{~s}$ is needed for the temperature to rise from $90 \mathrm{~K}$ to $300 \mathrm{~K}$. At $77 \mathrm{~K}$, critical current density is $1747 \mathrm{~A} / \mathrm{cm}^{2}$; this corresponds to a critical current of $343 \mathrm{~A}$. For an operating current of $400 \mathrm{~A}$, the current density is $2037 \mathrm{~A} / \mathrm{cm}^{2}$. Therefore, the warmer end of the lead is in the resistive regime and begins to heat up. An operating current of $350 \mathrm{~A}$ corresponds to a current density of $1783 \mathrm{~A} \mathrm{~cm}$. This is slightly higher than the critical current density at $77 \mathrm{~K}$ and the lead will heat up also but at a slower rate. The calculated bumout time is $5.8 \mathrm{~s}$, twice that for the

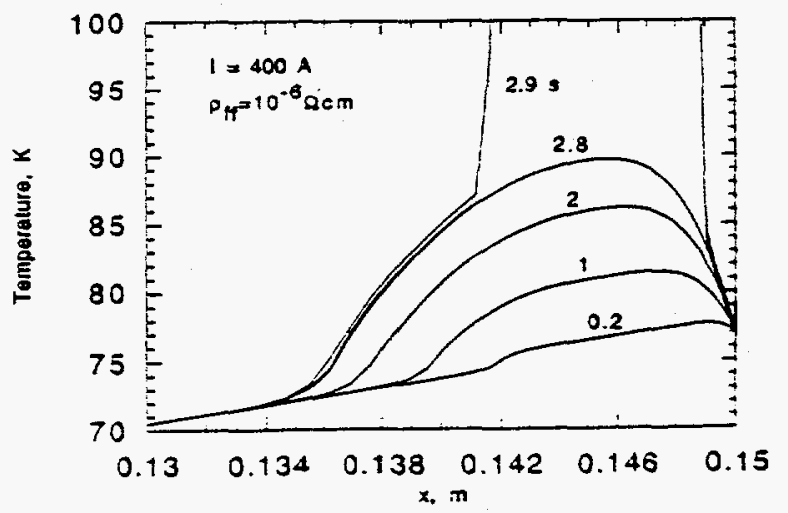

Fig. 5. Temperature distributions of BSCCO-2212 lead at different times $f \circ p_{f f}=10^{-6} \mathrm{~W}-\mathrm{cm}$ and operating current of $400 \mathrm{~A}$ 
case with an operating current of $400 \mathrm{~A}$. If the operating current is below $343 \mathrm{~A}$, the lead will be superconducting everywhere and there is no temperature rise, so the temperature distribution is like that shown in Fig. 3.

Fig. 6 shows the variation of maximum temperature with time for various flux flow resistivities and operating current $I=400 \mathrm{~A}$. Burnout time varies strongly with flux-flow resistivity. The flux-flow resistivity must be measured more accurately in order to predict correctly the bumout time.

Fig. 7 shows the variation of maximum temperature with time for various flux-flow resistivities and an operating current of $I=350 \mathrm{~A}$. The results are similar to that shown in Fig. 6 for $I=400 \mathrm{~A}$, except the burnout time is longer for $I=350 \mathrm{~A}$.

\section{CONCLUSIONS}

Transient behavior and burnout time of a conductioncooled BSCCO-2212 current lead are predicted by numerically solving a one-dimensional heat conduction equation. The results show that the temperature rise of the superconductor lead exhibited two distinct stages when the operating current density is greater than the critical current density. The temperature at the warmer end of the lead begins to rise slowly because the superconductor is in the dissipative (fluxflow) state. As soon as the local temperature reaches the critical temperature, the temperature begins to increase sharply and approaches the burnout temperature in a relatively short period of time because the normal state resistivity is much higher than the flux-flow resistivity of the superconductor. The time to reach burnout temperature depends strongly on the flux-flow resistivity, and there is a general lack of available data on the flux-flow resistivity of high-temperature superconductors.

\section{REFERENCES}

[1] I. R. Hull, "High temperature superconducting current leads," IEEE Trans. Appl. Supercond., vol. 3, pp. 869-875, 1995.

[2] J. R. Hull, "High temperature superconducting current leads for cryogenic apparatus." Cryogenics, vol. 29, pp. 1116-1123, 1989.

[3] R. C. Niemann. Y. S. Cha. J. R. Hull, W. E. Buckles, and M. L. Daugherty, "High temperature superconducting current leads for micro-SMES applications," IEEE Trans. Magn., vol. 30, pp. 2589. 2592, 1994.

[4] P. F. Herrmann, et al., "European project for the development of high TC current leads." IEEE Trans. Appl. Supercond.. vol. 3, no. 1, pp. $876-880,1993$.

[5] S. Y. Seol and I. R. Hull. "Transient analysis and burnout of high temperature superconducting current leads," Cryogenics. vol. 33, pp. $966-975.1993$.

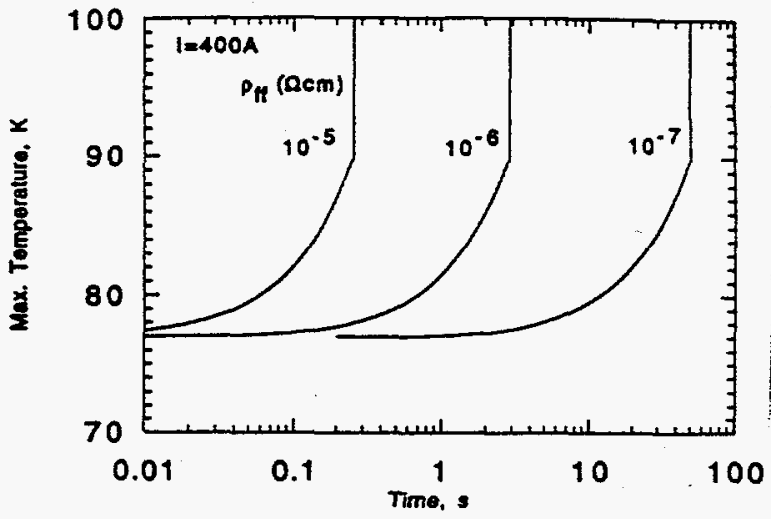

Fig. 6. Variations of maximum temperature with time for different values of flux-flow resistivity with $I=400 \mathrm{~A}$

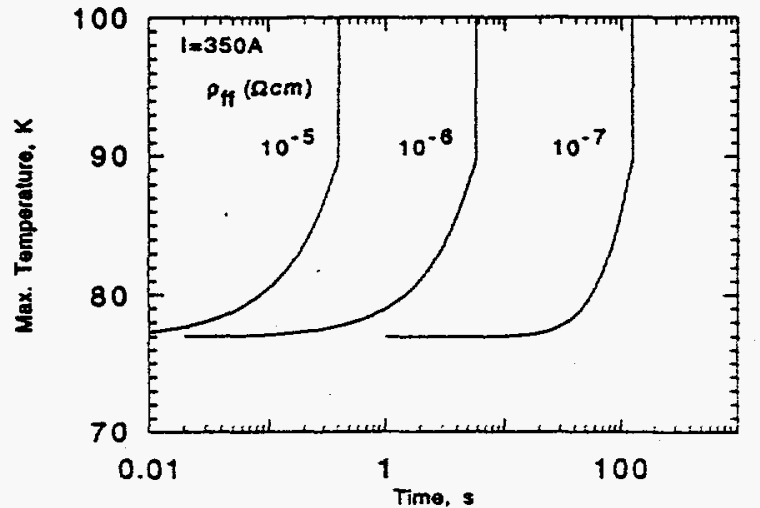

Fig. 7. Variations of maximum temperature with time for different values of flux-flow resistivity with $I=350$ A.

[6] S. Y. Seol, J. R. Hull, and M. C. Chyu, "Optimization of hightemperature superconductor current leads," IEEE Trans. Appl. Supercond., vol. 5, no. 2, pp. 785-788, 1995.

[7] H. Fujishiro, et al., "Low thermal conductive Bi-2223 tapes sheathed with Ag-Au alloys," IEEE Trans. Magn., vol. 30, pp. 1645-1650, 1994.

[8] A. Bejan and E. M. Cluss, "Criterion for burn-up conditions in gas cooled cryogenic current leads," Cryogenics, vol. 16, pp. 515-518, 1976.

[9] Yu. L. Buyanov, "Current leads for use in cryogenic devices. Principle of design and formulae for design calculations," Cryogenics, vol. 23, pp. 94-110, 1985.

[10] X. D. Wu. J. R. Fanton, G. S. Kino, S. Ryu, D. B. Mitzi, and A. Hapitulnik, "Thermal diffusivity of $\mathrm{Bi}_{2} \mathrm{Sr}_{2} \mathrm{CaCu}_{2} \mathrm{O}_{8}$ single crystals." Physica C, vol. 218. pp. 417-423, 1993.

[11] T. R. Askew. J. G. Nestell, R. B. Flippen, D. M. Graski. and V. McN. Alford. "Dynamic measurement of flux flow resistivity in $\mathrm{YBa}_{2} \mathrm{Cu}_{3} \mathrm{O}_{7}$ wires." IEEE Trans. Appl. Supercond., vol. 3, pp. 1398-1401. 1993. 